\title{
A Autonomia da Vontade nos Contratos Internacionais - Direito Brasileiro e Países do Mercosul: Considerações sobre a Necessidade de Alterações no Direito Internacional Privado Obrigacional do Bloco
}

$$
\text { Padia de eAxayjo }
$$

Doutora em Direito Internacional, Universidade de São Paulo. Mestre em Direito Comparado, George Washington University. Professora de Direito Internacional Privado e

Direito do Comércio Internacional, PUC/RJ e Professora Visitante do Mestrado em Direito Internacional e Integração Econômica da UERJ.

Palestra proferida no Curso de Especi alização "O Novo Direito Internacional" promovido pela Universidade Federal do Rio Grande do Sul, no dia 16 de julho de 1999 -

SUMÁRIO
I. Introdução;
II. O método do DIPr e a autonomia da
vontade;
III. Breve descrição do princípio da au-
tonomia da vontade no Brasil e no Mercosul;
IV. Conclusão.

\section{Introdução}

autonomia da vontade nos contratos internacionais é tema que sempre exerceu grande fascínio nos juristas ligados ao Direito Internacional Privado - DIPr, desde o século passado. Em 1927, NIBOYET já considerava sem exagero dizer que a teoria da autonomia da vontade era o tema mais difícil de todo o Direito Internacional Privado. ${ }^{1} \mathrm{Na}$ atuali-

1. Nyboyet, in Recueil de Cours, 1927. 
dade, OLE LANDO, ${ }^{2}$ esclarece que o direito das partes em escolher a lei que governará um contrato internacional é tão amplamente aceito nos países do mundo que se constitui em um desses princípios comuns ao âmago de todos os sistemas legais. $^{3}$

Esse interesse não tem apenas cunho acadêmico. A questão tem sido objeto da preocupação dos advogados militantes na área internacional, especialmente no momento da proposição e conclusão dos contratos internacionais. Assim, pode-se dizer que são características do tópico ser muito estudado, falado e discutido em negociações contratuais, justamente para que possíveis litígios futuros sejam evitados, ou sua decisão fique à mercê da interpretação dos tribunais, que poderiam fazê-lo em sentido oposto àquele desejado pelas partes. Esta é a razão também porque a discussão acerca da cláusula aparece muito pouco na jurisprudência pátria.

Neste estudo, discorreremos sobre o método do Direito Internacional Privado e a autonomia da vontade. Após, delinearemos a questão do dépeçage e a situação da autonomia da vontade no Brasil, com algumas conclusões finais.

\section{O método do DIPr e a autonomia da vontade}

Desde logo é preciso destacar que "autonomia da vontade no DIPr, utilizada nos Contratos Internacionais" nada tem a ver com o que os civilistas agora gostam de chamar de "autonomia privada" e que diz respeito a "faculdade" das partes em contratar.

Para o DIPr, "autonomia da vontade" significa permitir que partes escolham a lei aplicável ao contrato internacional. Essa possibilidade só existe no contrato internacional, pois nos contratos internos não é possível determinar qual o sistema jurídico que vai resolver suas questões. Aliás, essa é uma importante diferença entre contratos internos e os internacionais.

No contrato internacional, devido a sua característica de estar ligado a mais de um sistema jurídico, é preciso saber de qual desses sistemas será a lei aplicável. E hoje a faculdade das partes em determinar esta escolha é pacífica em vários países, seja por força de legislação interna, ou ainda de normas provenientes de tratados e convenções internacionais que abraçaram o princípio.

A crescente preocupação da comunidade internacional com a harmonização
2. Atribui-se a Charles Dumoulin, jurista francês do século XVI, o desenvolvimento do princípio da autonomia da vontade no Direito Atribui-se a Charles Dumoulin, jurista trancés do século XVI, o desenvolvimen que tratam da questão, culminando com o acớdãoInternacional Privado. São do início do século os primeiros acordãos franceses que tratam da questão, culminando com o acordãomarco American Trading Co. Para texto integral, ver ANCEL, Bertrand e LEQUETTE, Yves. Grands arrêts de la jurisprudence française de droit intermational privé. Paris: Ed. Sirey, 1987, pp. 66/73.

LANDO, Ole. Contracts in International Encyclopedia of Comparative Law. Vol. III, capítulo 24, Tübingen, Haia, Mohr/Mouton 1978 e The Conflict of Laws of Contract. General Principles, Recueil des Cours. Tomo 189, 1985.

No Brasil, veja-se, além de outros, STRENGER, Ireneu. Autonomia da vontade em Direito Internacional Privado. São Paulo: RT, 1968, p. 214, tese apresentada na USP para sua livre docéncia.

3. LANDO, Intemational Encyclopedia... cap. 24, p. 3. e uniformização dos conflitos de lei na área dos contratos internacionais justifica-se por ser esta uma área do direito de vital interesse no incremento do comércio mundial e na tendência de formação de blocos econômicos, que juridicamente se traduzem em processos integracionistas, como a União Européia, o Mercosul e o Nafta.

No que diz respeito aos contratos internacionais, veja-se, por exemplo, a ini ciativa européia que através da Convenção de Roma para determinação da lei aplicável aos contratos internacionais, já em vigor desde 1988, uniformizou o direito conflitual sobre o tema nos países do bloco. Isso se deu a partir da percepção de que o maior fluxo comercial intracomunitário também causou o aumento do volume de contratos internacionais e, conseqüentemente, os problemas decorrentes da lei a eles aplicada em caso de litígio.

No âmbito da América Latina, a codificação uniforme do Direito Internacional Privado é considerada como sendo um dos fatores imprescindíveis para se atingir a integração econômica do continente, e também aumentar a inserção desses países no contexto mundial. Sem uma uniformização jurídica não se pode fazer a integração econômica ou política, pois é preciso garantir aos atores desse processo uma base normativa com regras comuns, especialmente as regras conflituais de Direito Internacional Privado, de forma a garantir às partes privadas certeza e previsibilidade com relação às normas regentes de seus negócios.

E entre nós, esse movimento está em estágio adiantado, pois datam do século passado iniciativas dessa natureza. Como resultado, tivemos o Tratado de Lima, de 1878, os Tratados de Montevidéu (1898/ 99 e 1940), e o Código Bustamante, de 1928. A partir dos anos setenta, a atividade codificadora foi assumida pela OEA, que promoveu até a presente data cinco conferências interamericanas especializadas sobre a matéria (CIDIPs), resultando em 22 convenções. ${ }^{4}$

Evidentemente, muitos acharam, especialmente no passado, que dar às partes a faculdade de escolher a lei aplicável, era dar-lhes um poder quase legiferante, que só caberia aos Estados. Mas esta posição restou isolada com o passar dos anos, pois hoje se entende que a autonomia de contratar se estende até esse ponto nos contratos internacionais justamente por causa de suas características especiais.

E o que vem a ser escolher a lei aplicável? Significa, concretamente, inserir em um contrato internacional uma cláusula que estipule a lei à qual o contrato estará submetido. Esta poderá ser feita de forma expressa, o que certamente é mais seguro, ou ser inferida de forma tácita a partir da aná-

4. O Brasil sempre esteve presente às Conferências, tendo assinado a maioria das Convençōes. Nos últimos dois anos, a maioria delas entrou em vigor no Brasil, pelo que estamos, afinal, alinhados com o restante da América Latina. Para maiores informaçōes sobre o tema, veja-se: CASELLA, Paulo Borba e ARAUJO, Nadia de. Integraçào Jurídica Interamericana. São Paulo: LTr, 1998. Este livro congrega os estudos de vários juristas, analisando, separadamente cada uma das convençóes interamericanas e o seu Este lvro congrega os estudos de vários Junstas, analsando, separadant impacto no direito brasileiro. Conta, ainda, com um anexo com o texto das convençoes e um quadro com intormaçăo sobre sua
vigência no Brasil. 

xa margem a incertezas. ${ }^{5}$ lise da vontade das partes, situação que dei-

De plano é preciso dizer que a cláusula não é uma panacéia nem abrange todas as questões atinentes ao contrato. Como bem se vê dos estudos do método do Direito Internacional Privado, há regras de conexão para cada uma das situações que se apresentam. E antes de iniciar esse proces so de aplicação das regras determinadas é preciso classificar a situação jurídica dentro de um rol de qualificações, para em seguida, aplicar a regra pertinente, chegando-se afinal ao Direito vigente à situação concreta.

O contrato internacional traduz uma situação jurídica complexa, pois envolve diversos aspectos da relação jurídica, e nem todos poderão ser tratados conjuntamente. Assim, a cláusula que determina a lei aplicável ao contrato cuidará apenas daquelas questões que dizem respeito à substância $\mathrm{e}$ aos efeitos do contrato. No entanto, outras questões correlatas se colocam e que não serão reguladas por aquela lei assim determinada.

A realidade descrita acima chamase dépeçage ou fracionamento. É um mecanismo pelo qual um contrato é dividido em diferentes partes, que serão, cada uma delas, submetidas a leis diferentes. Pode ocorrer em dois níveis. No primeiro, pelo próprio sistema de DIPr, pois a substância pode ser regida por uma lei, enquanto, p.e, a capacidade das partes, a forma e a execução, po-

derá ser regida por outra. No segundo, o dépeçage decorre da própria autonomia das partes que têm a faculdade de determinar mais de uma lei aplicável ao contrato. Nesse nível, temos um desdobramento da noção de autonomia da vontade, pois além de escolher a lei para o contrato, poderão, ain$\mathrm{da}$, fazer "mais de uma escolha" em vista da complexidade de um determinado contrato multiconectado.

Historicamente o sistema de splitting do contrato originou-se na Alemanha, com os ensinamentos de SAVIGNY, que reputava aplicável a lei do local da execução para as obrigações contratuais, o que podia ter como conseqüência a aplicação de mais de uma lei ao mesmo contrato, se a execução se desse em mais de um país. SAVIGNY, um dos primeiros universalistas dos tempos modernos, argumentava que cada relação jurídica possuía uma sede. E ante a existência de mais de uma sede na relação jurídica contratutal, a lei do local de sua execução, poderia levar a aplicação de mais de uma lei, quando cada parte tivesse de executar sua obrigação em países diferentes. Para ele a obrigação e não o contrato, era a relação jurídica, razão porque era natural localizar cada uma delas em um país.

Atualmente, os contratos internacionais são operações que por sua complexidade podem estar ligados a mais de um ordenamento jurídico ao mesmo tempo, sendo, portanto, necessária a utilização de mais de uma regra de conexão para resol-

5. O direito anglo-saxão, através da regra da proper law of the contract, na ausência de cláusula expressa, procura determinar qual teria sido a vontade das partes, por entender que a lei deste país é que deveria ser aquela aplicável ao contrato. Deduz suas

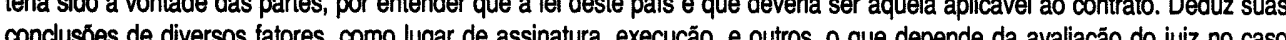
conclusoes de diversos fatores, como lugar de assinatura, execuçáa, e outros, o que depende da avaliaçáo do juiz no caso
concreto. ver cada um de seus aspectos. A ocorrência desse fenômeno implica na utilização do dépeçage. ${ }^{6}$

Dar-se-á o dépeçage quando em uma dada situação jurídica multiconectada for possível a incidência de normas de diferentes ordens jurídicas relativamente a diferentes aspectos do contrato. Considerando que há limitações à autonomia da vontade dos contratantes, e sua vontade não pode reger todos os aspectos do contrato, é preciso decompor o contrato em seus vários elementos, para aplicar a cada uma de suas partes a lei pertinente. Por exemplo, pode ocorrer em um contrato que a capacidade das partes seja regida pela lei pessoal, as obrigações das partes pela lei escolhida através da autonomia da vontade, a forma do contrato à lei da celebração, e se a transação implicar em transferência do domínio de um bem imóvel, à lei de sua situação jurídica.

JOÃO GRANDINO RODAS, ${ }^{7}$ alu de que não só é problema ínsito a todo contrato internacional a questão do direito aplicável, como também é preciso ser realista e aceitar ser impossível manter uma posição unitarista, porquanto aquela situação poderá vir a ser regida por mais de um sistema jurídico, aplicando-se o morcellement, acrescentando:

"A verdade é que, mesmo os unitaristas, como exemplificativamente NIBOYET, viram-se forçados a reduzir a unificação ao fundo do contrato, deixando eventualmente para outros direitos a regência da capacidade e da forma. Os partidários da pluralidade regencial aceitam ademais a dépeçage ou morcellement, da substância ou fundo contratual com a conseqüente aplicação de vários direitos.

Divide, ainda, os elementos de conexão do DIPr relativos às obrigações em quatro pontos: os relativos à capacidade da pessoa física; à capacidade da pessoa jurídica; aos aspectos extrínsecos ou formais e aos aspectos intrínsecos ou de fundo.

Como se não bastassem os problemas ocasionando a utilização de mais de uma lei, temos ainda dois outros fatores complicadores a serem levados em conta: 0 primeiro diz respeito ao foro eleito, e o segundo à ordem pública.

No primeiro caso, é preciso deixar bem claro que as cláusulas de eleição de foro e de lei aplicável não se confundem. Podese escolher um determinado foro para discutir os litígios advindos da relação contratual e naquele local utilizar-se a lei de um terceiro país no que diz respeito às regras materiais concernentes ao contrato em questão. No entanto, a redação e escolha dessas cláusulas devem ser feitas em conjunto pois embora autônomas, poderão ser interpretadas em conjunto, de modo que se o foro escolhido proibir a autonomia da atinentes a determinação da lei aplicável,

6. Veja a traduçăo do termo por Maria Helena Diniz, como sendo despedaçamento. Significa utilizar, ainda segundo a autora, um método analítico mais profundo de todos os elementos de conexão existentes no contrato internacional, qualificando-o mais perfeitamente. DINIZ, Maria Helena. Tratado Teórico e Prático dos Contratos. Vol. I, São Paulo: Saraiva, 1993, p. 473 e seguintes.

7. RODAS, João Grandino. Elementos de Conexăo do Direito Intemacional Privado Brasileiro, relativamente a obrigạ̧̋es contratuais, in Contratos Internacionais. Săo Paulo: RT, 1995.

Revista da Faculdade de Direito da UFRGS, v. 17, 1999 
vontade, a cláusula de lei aplicável poderá ser invalidada pelo juiz que estiver decidindo a questão em face de uma proibição da lei local. Desta forma, estão interligadas e as conseqüências de uma determinada escolha influi na outra cláusula.

$\mathrm{O}$ segundo problema diz respeito à ordem pública. O exercício da liberdade de escolher a lei pelas partes pode levar a uma lei que contenha dispositivos que não serão aceitos pelos critérios de ordem pública do foro, ou ainda, poderiam ser em contrárias à disposições de caráter imperativo do local em que o litígio está sendo decidido.

Do exposto se conclui que apesar da existência da liberdade das partes em determinar a lei aplicável a um contrato in ternacional, esta escolha possui limites que não podem ser ignorados, devendo obedecer, no caso concreto, a uma gama de fatores maior do que sua aparente amplitude à primeira vista. Apenas para relembrar o relatado acima, a autonomia da vontade sofre limites quando a situação requer a utilização do dépeçage e das regras, sejam elas imperativas ou parte da ordem públi$\mathrm{ca}$, existentes no foro utilizado para dirimir a controvérsia contratual.

8. Introdução ao Código Civi:

"Art. 13. Regulará, salvo estipulaçăo em contrário, quando à substância e aos efeitos das obrigaçóes, a lei do lugar onde forem contraídas.

Parágrafo único. Mas sempre se regerão pela lei brasileira: I - Os contratos exeqüiveis no Brasil; II - As obrigaçōes contraídas entre brasileiros em país estrangeiro; III - Os atos relativos a imóveis situados no Brasil; IV - Os atos relativos ao regime hipotecário brasileiro."

Lei de Introdução ao Código Civil:

"Art. 99. Para qualificar e reger as obrigaçōes, aplicar-se-á a lei do país em que se constituirem.

$\S 1^{2}$ Destinando-se a obrigação a ser executada no Brasil e dependendo de forma essencial, será esta observada, admitidas as peculiaridades da lei estrangeira quanto aos requisitos extrínsecos do ato.

$\S 2^{\mathbb{A}}$ A obrigação resultante do contrato reputa-se constituída no lugar em que residir o proponente."

9. BEVILAQUA. Princípios Elementares de Direito Internacional Privado. 4. ed., Rio de Janeiro: Freitas Bastos, 1944, p. 358 pessoal e, para a execução, a lei do lugar onde se efetuá-la.

Enunciou a lex contractus como sendo a do local da celebração, salvo quando tivesse havido estipulação em contrário, ou ainda, quando ofensiva ao direito nacional dos contratantes ou à ordem pública. ${ }^{10} \mathrm{Da}$ leitura do art. 13 e seu parágrafo único, não fica claro se a regra do caput é utilizada em conjunto com o parágrafo único ou se quando a execução fosse no Brasil, aplicar-se-ia a lei brasileira não só às questões da execução ou a estas questões e àquelas relativas à substância e efeito. No entanto, da jurisprudência da época verifica-se que a tendência era a aplicação da lei brasileirà para todos os aspectos dos contratos internacionais cuja execução se desse no território nacional (ou seja para as questões relativas à substância e à execução), o que nos aproximava bastante das regras seguidas pelos países do Prata - Argentina, Paraguai e Uruguai -, estabelecidas pelos Tratados de Montevidéu. De notar, ainda, que da jurisprudência estudada no período não houve ocorrências de discussões acerca da questão da autonomia da vontade. ${ }^{11}$

Todavia, apesar da opinião favorável de BEVILAQUA, muitos autores do período se posicionavam contrariamente ao

10. BEVILAQUA, op. cit., p. 359.

11. Para maiores detalhes sobre a jurisprudência brasileira, veja-se: ARAUJO, Nadia de. Contratos Intermacionais. Rio de Janeiro: Renovar, 1997, pp. 108 e seguintes.

12. ESPINOLA, Eduardo. Elementos de Direito Internacional Privado. Rio de Janeiro: Jacintho Ribeiro dos Santos, 1925, pp. 655/57.

13. MACHADO VILLELA, Álvaro da Costa. O Direito Internacional Privado no Código Civil Brasileiro. Coimbra: Imprensa da Universidade, 1921.

14. PONTES DE MIRANDA. Tratado de Direito Internacional Privado. Tomo I, Rio de Janeiro: Livraria José Olympio, 1935.

15. O tema da autonomia foi objeto de intensos debates em ambas as reunióes que resultaram nos Tratados, mas fol excluído na legislaçáo final. Para maiores detalhes, veja-se: ARAUJO, Nadia de, op. cit., pp. 142 e seguintes. 
simples supressão da expressão não poderia ter o condão de eliminar um princípio jurídico anteriormente aceito.

OSCAR TENÓRIO, ${ }^{16}$ ao comentar o art. 9, entendeu que a exclusão da teoria da autonomia da vontade na lei que substituiu a introdução deveu-se às severas críticas que aquela teoria havia recebido anteriormente. Entretanto, ao não estabelecer expressamente a teoria da autonomia da vontade, entende o autor que o art. 9응 também não a proibiu, deixando sua permissão à lei do contrato, ou seja, a sua aplicação de forma indireta, sempre que a lei da celebração o permitisse.

MIGUEL MARIA DE SERPA LOPES $^{17}$ ressaltou que na introdução de 1917, embora permitida, a autonomia da vontade não podia ser exercida senão no terreno supletivo. ${ }^{18}$ Já com relação à Lei de Introdução, de 1942, entendia que a omissão sobre a autonomia permitia-a apenas de forma indireta, ou seja, quando indicada pela lei do local da celebração, e ainda as. sim, apenas com relação a matéria supletiva. Pareceu-me posicionar-se contrariamente à autonomia, quando a lei aplicável fosse a lei brasileira, já que, a mudança na redação dera-se em razão da forte pressão exercida pela corrente doutrinária contrária a essa faculdade. ${ }^{19}$

E SERPA LOPES ainda criticava a posição de OSCAR TENÓRIO, pois sua formulação implicava, na verdade, em uma forma de reenvio, proibido pela lei, opinião compartilhada modernamente por FRANCESCHINI, que, em face da proibição expressa para a remissão, entendeu que a autonomia da vontade ali não está contemplada. ${ }^{20}$

Modernamente, a Lei de Introdução não tem atraído comentaristas, havendo poucos estudos recentes. Entre eles, o de MARIA HELENA DINIZ, ${ }^{21}$ que ao tratar do art. 9으, entende não ter o citado artigo contemplado a autonomia da vontade como elemento de conexão, pois trata-se de norma cogente e que não pode ser alterado pelas partes.

Assim, no que tange à prática diuturna, é preciso ser cauteloso, quando da redação de uma cláusula deste tipo em um contrato internacional, pois os tribunais brasileiros não enfrentaram a questão diretamente, nem parecem ter abraçado as teses pró-autonomia defendida por alguns doutrinadores.

$\mathrm{Na}$ nossa opinião, somente com a revisão da LICC, e adoção dos princípios consagrados na Convenção sobre o Direito Aplicável aos Contratos Internacionais,

16. TENÓRIO, Oscar. Lei de Introdução ao Código Civil Brasileiro. 2. ed., Rio de Janeiro: Ed. Borsai, 1955.

17. LOPES, Miguel Maria de Serpa. Comentários Teórico e Prático da Lei de Introdução ao Código Civil. Vol. II, Rio de Janeiro: Livraria Jacinto Editora, 1944

18. Id., ib., p. 315.

19. Id., ib., p.317.

20. FRANCESCHINI, José Inácio Gonzaga. A lei e o foro de eleição em tema de contratos internacionais, in Contratos Internacionais. São Paulo: RT, 1995, p. 103 e seguintes.

21. DINIZ, Maria Helena. Lei de Introdução ao Código Civil Interpretada. Săo Paulo: Saraiva, 1994, p. 246 e seguintes. realizada pela CIDP V, México, 1994, poder-se-á modificar a situação atual e assim, permitir de forma segura a utilização do princípio da autonomia da vontade pelas partes privadas em seus contratos internacionais.

No estágio atual da legislação brasileira, a escolha da lei aplicável a um contrato internacional, nos moldes reconhecidos atualmente na comunidade internacional, não encontra amparo seguro na legislação vigente, pois ali não estão expressamente contemplados.

Terminando os comentários sobre a legislação brasileira, é preciso falar da situação do Mercosul, pois não há uma posição uniforme até o momento, adotada por todos os seus integrantes, no que diz respeito à determinação da lei aplicável aos contratos internacionais, em face das normas encontradas nos quatro países, que além de contrárias à autonomia, adotam o critério da lei do lugar da execução para estabelecer a lei vigente ao contrato.

Desta forma, os contratos internacionais firmados no âmbito do Mercosul poderão ser regidos por normas diversas, a partir das regras de conexão de cada um dos países membros. Por isso, quando da elaboração de um contrato internacional em um desses países, há que se ter em mente as conseqüências quanto à lei aplicável do local da celebração e do local da execução, já que as normas em vigor não permitem que as partes escolham livremente a lei aplicável em nenhum dos países membros.

A situação atual é insatisfatória, podendo-se dizer que há uma verdadeira barreira jurídica a impedir a uniformização do DIPr dos contratos no Mercosul. É preciso modificar as normas hoje vigentes para o bom funcionamento do negócios no Mercosul. A inércia dos países membros com relação a esse tema pode ter conseqüências desastrosas, a longo prazo, nas relações comerciais do mercado comum, por contribuírem para a instabilidade das relações jurídicas.

Nesse sentido, a adoção do princípio da autonomia da vontade acabaria não só com as divergências existentes, como permitiria às partes optar pela lei que lhes fosse mais conveniente. Foram essas as idéias norteadoras da CIDIP V, que teve como resultado a aprovação da Convenção Interamericana sobre o Direito aplicável aos Contratos Internacionais, com intensa participação dos países membros do Mercosul.

Aguarda-se agora sua entrada em vigor para que se concretize a uniformização do direito internacional privado obrigacional do Mercosul, alinhando-o ao dos demais blocos integracionistas, como a Europa. Isso contribuiria para que o comércio no interior do mercado comum contasse com normas uniformes no que diz respeito à lei aplicável aos contratos internacionais, aumentando a segurança e a certeza jurídica necessárias ao incremento do comércio intra-regional.

\section{Conclusão}

Na Europa e em vários outros países, como os Estados Unidos, a autonomia da vontade é permitida, de forma expressa, em diversas leis. 
O mais interessante é o fato de que essa incorporação do princípio da autono mia se deu de fora para dentro, ou seja, a partir da codificação internacional o princípio entrou no ordenamento jurídico interno de diversos países.

Assim, o princípio da autonomia da vontade como norma de conexão aplicável aos contratos internacionais é considerado nos dias de hoje como regra universal. Adotado em alguns países através de complexas construções doutrinárias e jurisprudenciais, o princípio foi ganhando força em foros internacionais e nos últimos anos foi incorporado ao sistema jurídico de vários países, como norma cogente, através de convenções internacionais.

No Brasil a situação ainda não evoluiu, na esteira do desenvolvimento do prin cípio no plano internacional. A LICC, no seu art. $9^{\circ}$, não menciona o princípio. Em bora muitos juristas sejam a favor, enten demos que, em verdade, o princípio aqu está proibido. Esta afirmação decorre da lei tura do art. $9^{9}$ que não pode ser comparado com outras normas sobre o tema que o per mitem expressamente, como por exemplo na Convenção sobre lei aplicável aos con tratos internacionais, verbis:

vel

"Determinação do direito aplicá-

\section{Art. $7^{\circ}$}

O contrato rege-se pelo direito escolhido pelas partes. $O$ acordo das par tes sobre esta escolha deve ser expresso ou, em caso de inexistência de acordo expresso, depreender-se de forma eviden- te da conduta das partes e das cláusulas contratuais, consideradas em seu conjunto. Essa escolha poderá referir-se à totalidade do contrato ou a uma parte do mesmo.

A eleição de determinado foro pelas partes não implica necessariamente a escolha do direito aplicável."

E a jurisprudência tampouco esclareceu a matéria, como se vê da análise dos poucos casos existentes. Nos casos pesquisados, notamos que os juízes usaram o método conflitual para determinar a lei aplicável, sempre encontrando como resultado a lei brasileira ou a lei estrangeira, a partir de uma interpretação literal do art. 9․ caput.

Por isso, apesar de sermos favoráveis à autonomia, especialmente em face do aumento dos contratos internacionais decorrentes do incremento comercial em razão dos processos de globalização e integração regional, concluímos que a legislação vigente não contém nenhuma norma indicativa da sua aceitação.

Assim, somente através da substituição do art. 9ํ da LICC por normas que expressamente permitam a autonomia da vontade teremos uma modificação da situação atual. Finalizando, sugerimos que o Brasil adote a Convenção Interamericana sobre o direito aplicável aos contratos internacionais, não só para regular os contratos internacionais entre os parceiros latino-americanos mas também como regra conflitual à todas as relações contratuais internacionais, substituindo, afinal o inadequado art. 9 da LICC.

\title{
Mercosur - Una Introduction
}

\author{
Ricasdo Luis Laxenretti
}

Professor de la Universidad de Buenos Aires

\section{Descripcion Del Sistema Juridico Del Mercosur}

\section{Introducción: los vicios del jurista}

a actitud de los juristas frente a Mercosur es un verdadero desafio, $y$ encierra algunos vicios.

Por un lado,estàn quienes aceptan la marginaciòn, ya que es un tema de los economistas, quienes se ocupan de las cosas verdaderamente importantes.- Ello es hoy insostenible, ya que ha quedado demostrado que la apertura indiscriminada de campos desregulados provoca efectos distorsivos que afectan la eficiencia econòmica $y$ desertifican la sociedad humana.-

Una vez decididos a participar, los juristas solemos ser perezosos : todo lo que hace falta es imitar lo que se ha hecho en europa.- De este modo, el Mercosur serìa una suerte de "uniòn europea en desarrollo", con lo cual no se hace màs que reeditar los vicios imitativos y la cultura de la traducciòn, que tanto daño hicieran en los àmbitos nacionales.-
La cultura jurìdica occidental suele ser dividida en anglosajona y continental europea, y pareciera que las discusiones no tienen cabida.- Sin desconocer las virtudes, olvidamos los desastres producidos por ambas culturas jurìdicas que han dibujado un final de siglo del cual no pueden enorgullecerse demasiado. - Imitar lo bueno,pero ensayar una cultura jurìdica latinoamericana, o mercosuriana es una buena tarea : la protecciòn ambiental, del consumidor, la igualdad, el pluralismo, el eclecticismo, son caracterìsticas que debemos recuperar para el diseño de una sociedad jurìdicamente organizada.-

En el plano formal se ha utilizado la palabra "Código" para mencionar el sistema jurídico del 'Mercosur.- Evidentemente, si se identifica al Código con una regla estatal ordenada racionalmente que establece la existencia de axiomas que son aplicables al caso concreto mediante un juicio deductivo, no puede decirse que esa sea la situación en el Mercosur.-

Ello no significa inhibir su utilización para expresar otros sentidos. - En un primer 